African Research Review An International Multidisciplinary Journal, Ethiopia

Vol. 9(1), Serial No. 36, January, 2015:183-198

ISSN 1994-9057 (Print)

ISSN 2070--0083 (Online)

DOI: http://dx.doi.org/10.4314/afrrev.v9i1.15

\title{
Knowledge, Attitude and Practice of Family Planning Among Air Men in the Sam Ethnan Air Force Base, Ikeja, Lagos
}

\author{
Ekhareafo, Daniel Ofomegbe \\ Department of Theatre Arts and Mass Communication \\ University of Benin \\ Benin City, Edo State, Nigeria \\ E-mail: talk2ofomegbe@gmail.com. \\ Phone No: +2348032682533
}

$\&$

\section{Moyaki, Mayowa Gabriel}

Research Fellow, Department of sociology, University of Ibadan

Ibadan, Oyo State, Nigeria

E-mail: Isaiah818gabriel@gmail.com

Phone no: +2348030987254

\begin{abstract}
This study examined the knowledge level, attitude to and the practice of Family Planning among Airmen in Nigeria. It was hypothesized that knowledge of Family Planning, number of children and religion affect the use of Family planning. The study also identified socio-demographic variables and other factors associated with male use of Family Planning. Rational Choice Theory (RCT) was adopted as the theoretical basis for the study. Primary data from 232 respondents were obtained
\end{abstract}


from questionnaire administered on the sample population. This was complemented with In-Depth Interviews among selected Airmen. Respondents were broadly categorized according to their ranks from ACM to AWO. Quantitative data were analysed using frequency tables and chi-square, while document analysis was employed for qualitative data. High knowledge of family planning was a predictive of the use of family planning while the study was not able to establish any significant relationship between the number of children and the use of family planning. Religion did not have any significant relationship with the use of family planning, but 63.4\% of men agreed that their religion/denomination encouraged the use of Family Planning. The study therefore encouraged improvement in the use of other media of communication like Family Planning tracts, handbills, and billboards for wider reach. Also Family Planning Clinic should be made to be more men-friendly so as to attract the patronage of more men.

Key words: Family Planning, Airmen, Knowledge, Attitude, Practice, Air men, Nigeria.

\section{Introduction}

Nigeria is currently the most populated country in Africa. The UNFPA (2010) predicted that the population of Nigeria will climb from its current 160 million to 730 million people by the year 2100 , if the UN prediction is correct, Nigeria would become the third most populated country in the world behind India and China given that other nations growth rate remains static.. This high population however has not been in commensurate with the level of social and economic development of the country. Currently, more than $70 \%$ of Nigerians live below the international poverty line according to the UNFPA (2010). Population growth in Nigeria represents an annual population growth rate of $3.2 \%$ or 5.6 million people per annum. Rosenthal (2012), postulated that in a quarter-century at the rate Nigeria is growing, 300 million people- a population about as big as that of the present day United States- will live in a country roughly the size of Arizona, New Mexico and Nevada. She further posited that as graduates pour out of high schools and universities, Nigeria's unemployment rate is nearly $50 \%$ for urban area ages 15 to 24 - driving crime and discontent. In October 2011, the United Nations announced that the global population had breached seven billion, and would expand rapidly for decades, taxing natural resources if countries cannot better manage the growth. Nearly all the increase is in Sub-Saharan Africa, where the population rise outstrips economic expansion.

Across Sub-Saharan Africa, alarmed governments have begun to act, often reversing longstanding policies that encouraged or accepted large families. Nigeria made contraceptives free in 2011, and officials are promoting smaller families as key to economic salvation, holding up the financial gains in nations like Thailand as inspiration, Rosenthal (2012). 
National Family Planning programmes have been an important instrument in accelerating global fertility decline and in restricting ultimate World population to a level probably below 10 billion. Caldwell, Philip, and Barkat E-Khuda (2002), noted that family planning began to come into being after 1950 and will probably go out of existence in most of the world's region by 2050 .

Isiugo-Abanihe, (1996) contends that family planning is an organized effort essentially to ensure that couples, who want to have fluent family size or to space their children have access to contraceptive information and services and are encouraged to use them as needed. Park, (2002) defined family planning as a way of living which is adopted voluntarily upon the basis of knowledge, attitude and responsible decision-making by individuals or couples in order to pin the number, family and spacing of the children that they want, so as to promote the health and welfare of the family group and contribute to the advancement of the society.

Today in Nigeria family planning issues are primarily anchored on the National Population policy. One of the implementation strategies, of the 2004 National population policy, focuses attention on the male reproductive health.

According to the document men play three significant roles in reproductive health concerns

(i) Men have reproductive health needs of their own,

(ii) The reproductive and sexual behavior of men has implications for the health well-being of their spouse and children,

(iii) Men play a dominant role in decision making about reproductive and sexual matters in the family and community settings (FGN, 2004).

The effort to reach out to men in the context of a broader development effort holds promise, especially in countries where traditional gender roles and provision prevail, where reproductive health remains a woman's concern and where general in equalities impede spousal support and communication (Lundgren et al, 2005).

It is against this backdrop that this study is carried out. This study investigated the knowledge, Attitude and Practice of family planning methods among AIRMEN in the Sam Ethnan Airforce Base, Ikeja, Lagos State. Knowledge and practice of family planning methods in this study was not be limited to just knowing the number of men using condom and having vasectomy, but also included the numbers of men who encourage and support their partner and their peers to use family planning. 


\section{Statement of problem}

Despite the important roles played by men in sexual and reproductive health there appears not to enough knowledge and involvement of men in family planning especially among military men. This is manifested in the high population growth in many of the barracks. Studies carried out on male roles in family planning have tended to ignore members of the military establishment, who by the nature of their job can be vulnerable especially in the issues concerning reproductive health. It is in view of this that the study examines the knowledge, attitude, and practice of family planning among Air Men in the Sam Ethnan Air Force Base, Ikeja, Lagos

Specifically, the study sought to achieve following objectives:

(i) Whether there is a significant relationship between knowledge of Family Planning and the use of family Planning among Airmen.

(ii) Whether the perception of AIRMEN toward family planning methods has a significant impact on the usage.

(iii) Whether there is a significant relationship between the number of children and the use of family planning among AIRMEN.

\section{Male involvement in family planning}

In recent times, many in the reproductive health field have come to appreciate the need for the constructive involvement of men in programs and services. The 1994 International Conference on Population Development (ICPD) held in Cairo articulated why and how male involvement should occur. Recognition is growing that men are interested in and need reproductive health information and services, both for their partners and for themselves (Drennan 1998; Ringheim 2002; AGI 2003; Lundgren et al 2005), and that the reproductive health of individuals depends heavily on the relationship between two people concerned. Awareness has increased that services should be directed not only towards women but also towards men and couples (Becker 1996; Ringheim 2002; Lundgren et al 2005).Before the current concern for male involvement began, reproductive health issues and services had become synonymous with women's reproductive health, and men were assumed to have no special interest in such matters. Indeed, the characteristic lack of male involvement in reproductive initiatives, including family planning, is a major obstacle to a speedy fertility decline in sub-Saharan Africa given the considerable authority and power vested on men as decision makers in the home and society (IsiugoAbanihe, 2003; Nwokocha 2006). Ignoring the role that men play in this area may have contributed to the halt in the rise of contraceptive prevalence in some part some parts of the world, and has certainly led to the growing dissatisfaction among women about the disproportionate burden they have to bear for contraception (Ringheim, 1996). 
The decision making process underlying family planning equally has implications for the timing of pregnancy and prenatal care. The likelihood is higher for couples that space births with at least two years interval to readily defray the cost of prenatal care than couples who give birth at shorter intervals, especially in a harsh economic environment. Also, depending on the level of agreement between couples on family planning dynamics, a husband might withhold or withdraw both financial and emotional support at various stages of pregnancy. Nwokocha, (2006) observed the attitude exhibited by husbands at each of these integral stages (family planning, pregnancy, prenatal care, delivery and postpartum) of pregnancy affects the psychological disposition of women which is critical to maternal outcomes. Only recently have FP associations recognised the importance of men's role and Motivation in fertility decision making, particularly in Africa. But now that this has been recognised, the question is "what can FP and reproductive health programmes do to encourage men's cooperation?" (Hawkins 1992, Ringheim 1996). Experts are now asking how men can be more supportive and involved in FP (PRB incorporated, 1990; also in Olawepo \& Okedare, 2006). Current UN figures show that Worldwide, about a third of all couples practising FP rely on methods that require male cooperation, including modern methods such as the use of condoms and male sterilization (Olawepo \& Okedare, 2006). For men, according to Odimegwu C.O. (1999); the critical variables that influence the probability that they will use FP are religion, and ethnicity. Other predicators are FP approval, media exposure, place of residence and spousal approval and communication.

\section{Theoretical framework}

\section{The rational choice theory}

Rational Choice Theory was considered appropriate for this study. The Rational Choice Theory has its strength in predicting intentions and choices of actors. A pioneering figure in establishing Rational Choice Theory (RCT) in sociology was George Homans (1961), who set out a basic framework of exchange theory, which he grounded in assumptions drawn from behaviourist psychology ( Halcli, and Webster, 2000). During the 1960s and 1970s, extended and enlarged his framework, and they helped to develop more formal, mathematical models of rational action (see also Coleman 1990). Rational choice theory is a theory that sees individual self-interest as the fundamental human motive and traces all social activities back to acts of rational calculation and decision making that are supposed to have produced them. In RCT, individuals are seen as motivated by the wants or goals that express their 'preferences'. They act within specific, given constraints and on the basis of the information that they have about the conditions under which they are acting. At its simplest, the relationship between preferences and constraints can be seen in the purely technical terms of the relationship of a means to an end (Halcli, \& Webster, 
2000). As it is not possible for individuals to achieve all of the various things that they want, they must also make choices in relation to both their goals and the means for attaining these goals. Rational choice theory holds that individuals must anticipate the outcomes of alternative courses of action and calculate that which will be best for them. Rational individuals choose the alternative that is likely to give them the greatest satisfaction (Carling 1992:27). Coleman (1990b:13) rational choice is based on the assumption that "an individual act purposively towards a goal, with the goal (and thus the actions) shaped by values or preferences". Actors act to maximise utility, or satisfaction of their needs and wants. The focus in RCT according to Ritzer (1996), is on actors. Actors are seen as being purposive, or as having intentionality. Friedman and Hechter (1988) identified two major constraints on action that must be taken into consideration. The first is the scarcity of resources. Actors have different resources as well as differential access to other resources. For those with lots of resources, the achievement of ends may be relatively easy while those with few, if any, resources, the realisation of ends may be difficult or impossible. A second source of constraints on individual action is social institutions. As Friedman and Hechter (1988), put it,

an individual typically will find his or her actions checked from birth. To death by familial and school rules; laws and ordinances; firm policies; choices, synagogues and mosques; and hospitals and funeral parlours. By restricting the feasible set of courses of action available to individuals, enforceable rules of the game- including norms, Laws, agendas, and voting rules- systematically affect social outcomes (202).

These institutional constrictions provide both positive and negative sanctions that serve to encourage certain actions and discourage others.

Rational choice theory suggests that an Air Man with the goal of preventing unwanted pregnancy has a range of methods to achieve this end. However, if the man is sexually active and indulging in sex, but not wanting to give birth to children, given constraints and on the basis of the information that he has, he may decide to use any FP method. The other alternative to FP may be abortion hence, the use of FP is a more rational decision than abortion, so such individual will favour the use of FP. Finally the importance of information in making rational choices was emphasized by Friedman and Hechter (1988). The quality and quantity of information available to an individual on the FP methods is vital in order to make a rational decision on which method to use. Individuals with quality knowledge of FP would favour the use of FP over abortion and also help to space children in the family, thereby giving birth to children that can be properly catered for. This is based on the principle of informed 
choice in FP. This invariably will also help to control population growth. Lack of qualitative knowledge of FP therefore, can constitute barrier to FP.

\section{Methodology}

The study adopted a cross-sectional research design. Fieldwork was carried out mainly among Air men from the rank of Air Craft Men (ACM) to Air Warrant Officer (AWO) in the Air Force Base, Ikeja. Data were collected using both the qualitative and quantitative techniques for complementarity and robustness. The qualitative method of data collection involved the In-Depth Interview (IDI), which was conducted on ten Air men based on availability of respondents and the willingness to respond to the thematic issue, given that family planning is a general public health and social issue. It also used parallel with the survey to gather information on the availability of family planning clinic, services available, volume of patronage, awareness and other information that are germane to the knowledge attitude and practice of family planning in the Sam Ethnan Airforce Base, Ikeja.

The quantitative method technique on the other hand, involved a multistage sampling method. Air Force base Ikeja was randomly selected from three Air Force bases in Lagos. The next stage was the selection of 300 Air men cutting across the seven rank categories that make up the Air men cadre and questionnaires administered. However, 232 questionnaires were returned.

Data generated from the questionnaire were then analyzed using the Statistical Package for Social Sciences (SPSS). A descriptive analysis of data was undertaken using bivariate frequency distribution and cross-tabulation of variables, whose associated influence impact strongly on the study. Qualitative data were analyzed using manual document analysis. Both the qualitative and quantitative data were jointly presented.

For the purpose of this study, 'Perception' and 'Attitude' are either positive or negative. They are positive when thoughts, opinions and feelings that inform Air men's behavior support family planning use; and negative when impressions, views, and way of thinking discourage Air men's use of family planning. 


\section{Data presentation and analyses}

Table 2: Distributions of respondents by methods of preventing pregnancy, awareness of family planning and prevention of abortion

\begin{tabular}{llc}
\hline Questions and responses & Frequency & Percentage \\
\hline Methods of preventing pregnancy & & \\
Modern method & 194 & 91.1 \\
Traditional method & 19 & 8.9 \\
Total & 213 & 100 \\
Awareness of Family Planning & & \\
Yes & 219 & 95.6 \\
No & 10 & 4.4 \\
Total & 229 & 100.0 \\
FPcan help prevent abortion & & \\
Yes & 186 & 81.6 \\
No & 42 & 18.4 \\
Total & 228 & 100.0 \\
& & \\
\hline
\end{tabular}

Table 3: Distributions of respondents by knowledge of FP methods and sources of information

\begin{tabular}{llc}
\hline Questions and responses & Frequency & Percentage \\
\hline $\begin{array}{l}\text { Family planning method } \\
\text { traditional methods }\end{array}$ & & \\
$\begin{array}{l}\text { modern methods } \\
\text { combination of traditional and modern }\end{array}$ & 23 & 10.35 \\
methods & 66 & 29.72 \\
others & 108 & 48.68 \\
Total & 25 & 11.25 \\
& 222 & 100 \\
Source of family planning information & & \\
radio & & \\
television & 80 & 35.2 \\
newspaper/magazines & 27 & 11.9 \\
peers/colleagues & 72 & 31.7 \\
family planning clinic & 17 & 7.5 \\
pamphlets & 25 & 11.0 \\
others & 5 & 2.2 \\
Total & 1 & .4 \\
& 227 & 100.0 \\
\hline
\end{tabular}

Copyright $@$ IAARR, 2015: www.afrrevjo.net

Indexed African Journals Online: www.ajol.info 
Respondents were asked to provide information on the method of family planning they know. The respondents were allowed to choose more than one options. Responses were classified into traditional and modern methods, combination of traditional and modern methods (Where a respondent chose the two methods), and others methods not listed. Respondents who chose the combination of the two methods were more than the respondents who had knowledge of only traditional methods, or modern methods, or other methods. Overall, a large percentage of the respondents $(48.68 \%)$ reported that they know a combination of both the traditional family planning methods and the modern family planning methods. Also $29.72 \%$ of respondents know only the modern methods, $10.35 \%$ know the traditional methods only and $11.25 \%$ know other methods.

Table 3 also provides information on respondents' sources of information on family planning. Majority of respondents get information from the mass media, which include Radio, Television, Newspapers/Magazines, and Pamphlets. Radio is the most frequent source of family planning information for respondents (35.2\%), Newspapers/Magazines has $31.7 \%$ of respondents getting their information from it, while Television provides information on family planning for $11.9 \%$ of respondent and pamphlet is the least mass media source with $2.2 \%$ of respondents.

Respondents were asked if they were aware of the family planning unit at NAF 445 hospital 10.13 said yes, while 89.97 said no. this is manifest from figure 1. Respondents were also asked whether they have ever visited the FP unit in the NAF 445 hospital for any service. Figure 1 shows that more than half of respondent $66.7 \%$ had never visited the FP unit, while 33.3\% had visited the FP unit in the hospital. This may be due to the fact that majority of the services provided there and in most FP units are geared towards catering mostly for women

Figure 1:

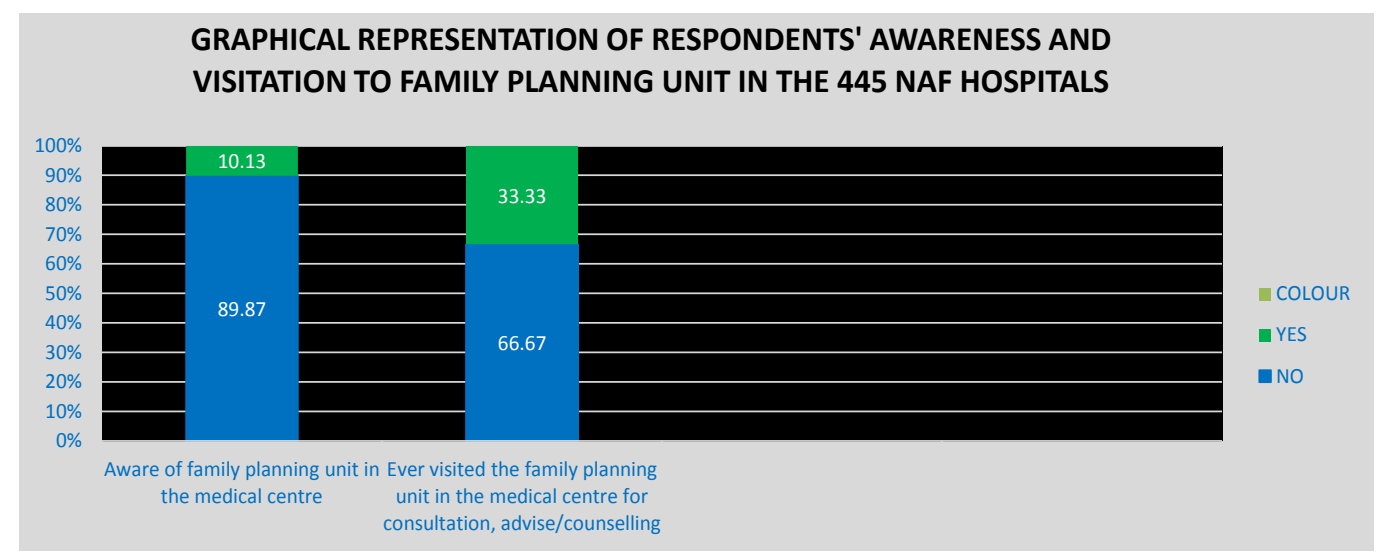

Copyright $@$ IAARR, 2015: www.afrrevjo.net Indexed African Journals Online: www.ajol.info 


\section{Use of family planning}

The use of contraception provides a measure of the experience of the population with family planning. Use of family planning in this study refers to the present use of family planning. Respondents were asked to provide response to current use of family planning and the particular method they are using. Table 5 presents the percentage of Airmen presently using family planning and the method they are using. More than half (59.4\%) of the respondents are presently using family planning. This result is similar to that presented in the NDHS 2008, which has the peak level for family planning use among men at $52 \%$. Also majority of respondents using family planning prefer the male condom, while minorities use withdrawal methods and periodic abstinence. This may be due to lack of ready alternative FP methods.

Table 5: Distributions of respondents by use of family planning

\begin{tabular}{lll}
\hline Questions and responses & Frequency & Percentage \\
\hline Currently using family planning & & \\
Yes & 126 & 59.4 \\
No & 86 & 40.6 \\
Total & 212 & 100.0 \\
If yes & & \\
Condom & & 79.8 \\
Withdrawal method & 95 & 16.0 \\
Periodic abstinence & 19 & 4.2 \\
Total & 5 & 100.0 \\
& 119 & \\
\hline
\end{tabular}

\section{Marital statuses, contraceptive used, and the particular FP method used}

The study also investigated the relationship between marital status and the use of FP. The results show in Table 8 below that $57.7 \%$ of singles and $60.3 \%$ of married respondents are currently using FP; also there is no significant relationship between the marital status of respondents $\mathrm{df}=2 ; \mathrm{p}<0.05$ and the particular method they are using. Among singles, $80.5 \%$ of respondents used the condom, while $61.2 \%$ of married respondents also use the condom. However, this result cannot be said to be conclusive because of the number of singles (71 respondents) involved in the study. Hence it may not be a true reflection of the general trend among singles. 
Table 8: Distribution of Respondents by currently using FP and Methods Used

\begin{tabular}{|l|l|l|l|}
\hline Variables & $\begin{array}{l}\text { Single } \\
\text { N(percentage })\end{array}$ & $\begin{array}{l}\text { Married } \\
\text { N(percentage })\end{array}$ & Total \\
\hline $\begin{array}{l}\text { Currently using family } \\
\text { planning }\end{array}$ & & \\
Yes & $41(57.7 \%)$ & $85(60.3 \%)$ & 126 \\
No & $30(42.3 \%)$ & $56(39.7 \%)$ & 86 \\
Total & $71(100 \%)$ & $141(100 \%)$ & 212 \\
\hline \multicolumn{3}{|c|}{ DF 4 P<0.607 } \\
\hline Method Used & $33(80.5 \%)$ & $52(61.2 \%)$ & 85 \\
Condom & $3(19.5 \%)$ & 41 \\
Withdrawal method & $41(100 \%)$ & $85(100 \%)$ \\
Total & $\mathrm{DF}=4 \mathrm{P}<0.05$ \\
\hline \multicolumn{3}{|l|}{} \\
\hline
\end{tabular}

\section{Knowledge of FP and the use of FP}

Table 9 shows the relationship between the knowledge of FP and the use of FP. The results show that respondents knowledge of FP $(D F=2, p<.004)$ significantly influenced the use of FP. Among respondents with low level of knowledge of family planning, less than half (44.4\%) use FP. However, among respondents with moderate knowledge, more than half (64.7\%) does not use FP, while more than half (64.5\%) of respondents with high knowledge use FP.

This result shows that there is a significant increase in the use of FP among Airmen as knowledge of FP increased. This result may be due to the fact that the study population is a knowledgeable population. The knowledge of particular importance to men includes receiving proper information about modern contraceptives that are available to be chosen in a FP program for husband and wife. 
Table 9: Respondents' knowledge of FP and use of FP

\begin{tabular}{|l|l|l|l|}
\hline \multirow{2}{*}{ Level of knowledge } & \multicolumn{2}{|l|}{$\begin{array}{l}\text { Do you presently use any family } \\
\text { planning method? }\end{array}$} & \multirow{2}{*}{ Total (\%) } \\
\cline { 2 - 3 } & Yes (\%) & No (\%) & $18(100 \%)$ \\
\hline \multirow{2}{*}{ Low knowledge } & $8(44.4 \%)$ & $10(55.6 \%)$ & $34(100 \%)$ \\
\cline { 2 - 4 } & $12(35.3 \%)$ & $22(64.7 \%)$ & $152(100 \%)$ \\
\hline \multirow{2}{*}{ High knowledge } & & & \\
\hline Total & & $54(35.5 \%)$ & $204(100 \%)$ \\
\hline Df $=2 ; p<0.004$ & $118(57.8 \%)$ & $86(42.2 \%)$ & \\
\hline
\end{tabular}

\section{Number of children and use of FP}

Couples use family FP methods either to limit family size or to delay the next birth. Couples using FP as a means to control family size (i.e. to stop having children) adopt contraception when they have already had the number of children they want. When contraception is used to space births, couples may start to use FP earlier, with the intention of delaying a pregnancy. This may be done before a couple has had their desired number of children. The number of children given birth to in a population may be an indication of the success or otherwise of FP. Respondents in this study were asked to indicate the number of children they have. Table 10 shows that the number of respondents with more than four children was far less than those with one to four children. The result as presented in table 11 also shows that the use of FP significantly increased with increase in the number of children. Among those having 1-2 children, $58.1 \%$ use FP, while $82.0 \%$ of those having $3-4$ children, and $72.7 \%$ of those having 5-7 children also use FP. This may be due to respondents either wanting to limit family size, stop having children, delay the birth of the next baby or conform to the Nigerian federal government policy of having only four children.

However, the table also shows that the chi-square result of the number of children is not significant at $\mathrm{df}=2 ; \mathrm{p}<0.023$, meaning there is no significant relationship between respondents' number of children and the use of family planning. 
Table 10: Respondents number of children and use of FP

\begin{tabular}{|c|c|c|c|}
\hline \multirow[t]{2}{*}{ Number of children } & \multicolumn{2}{|c|}{$\begin{array}{l}\text { Presently using any family planning } \\
\text { methods }\end{array}$} & \multirow[b]{2}{*}{ Total N (\%) } \\
\hline & Yes N (\%) & No N (\%) & \\
\hline \multirow[t]{2}{*}{ 1-2children } & $36(58.1 \%)$ & $26(41.9 \%)$ & $62(100 \%)$ \\
\hline & $41(82 \%)$ & $9(18 \%)$ & $50(100 \%)$ \\
\hline $\begin{array}{l}\text { 3-4 children } \\
\text { 5-7 children }\end{array}$ & $8(72.7 \%)$ & $3(27.3 \%)$ & $11(100 \%)$ \\
\hline Total & $85(69.1 \%)$ & $38(30.9 \%)$ & $123(100 \%)$ \\
\hline \multicolumn{4}{|l|}{$\mathrm{df}=2 ; \mathrm{p}<0.023$} \\
\hline
\end{tabular}

\section{Discussion of findings}

This study revealed that there is a high knowledge and awareness level of Family Planning among Air Men, with $95.6 \%$ of Airmen having awareness. This result is similar to that presented in the NDHS 2008, that the knowledge of any contraceptive method is wide spread in Nigeria, with $90 \%$ of all men knowing at least one method of contraception. The difference in the result may be a function of the level of education, and place of residence of the Air Men. NDHS 2008 also reported that knowledge of any contraceptive among men showed greater differentials by place of residence, zone, educational level and wealth quintile.

Also, majority of respondents (81.6\%) agree that family planning can prevent abortion. In a study carried out by Terefe and Larson (1993) among Ethiopian men, it was concluded that men agreed that the use of modern contraceptives can help can help prevent unwanted pregnancy thereby curtailing the rate of abortion. Also, it may be due to the fact that some respondents perceive that abortion may endanger the life of their spouse, hence the need to prevent unwanted pregnancy by using FP, this view was expressed by respondents in the In-Depth Interview. While $47.8 \%$ of respondents strongly agree than family planning can help a couple delays and/ or prevent pregnancy, $43.17 \%$ agree to the assertion, while $17.3 \%$ disagree and $1.7 \%$ strongly disagrees.

The main source of information about Family Planning for Airmen is the Mass Media with the Radio as the primary medium of information. 35.2\% of respondents got their information from the Radio, 31.7 got it from Newspapers/Magazines, $11.9 \%$ from Television, $11.0 \%$ from the FP Clinic, $7.5 \%$ 
from Peers/Colleagues, $2.2 \%$ from Pamphlets and $0.4 \%$ from other sources. This result is similar to that presented in NDHS 2008 that the radio is the most frequent source of family planning message for both men and women. This result shows that the mass media plays a very important role in providing information on family planning to Airmen.

Generally, respondents have a good perception of Family Planning. Despite identifying the different side effects of FP like Bleeding, Late Conception, Fatness, Irritations and Complications, majority of the respondents (84.9\%) agreed that they were going to encourage their spouse/ partners to use FP. Toure (1996), has stated that male involvement in FP means more than increasing the number of men using condoms and having vasectomies; male involvement also includes the number of men who encourage and support their partner and their peers to use FP. Also 84\% of respondents agreed that they were going to use Family planning themselves in the future. However with the great awareness of the presence of a Family planning unit in the NAF 445 hospital, only $33.33 \%$ of the respondents have ever visited the unit, while $67.67 \%$ have not. This is in line with the sentiment expressed in the In-Depth Interview by a respondent: Why should I go to there? (i.e. FP UNIT), when all they teach there is meant For women alone?. Generally, the attitude of Airmen towards FP is good. Odimegwu (1999) was able to demonstrate that people's perception of FP affect whether they will use it.

The use of FP showed that $59.4 \%$ of respondents are presently using FP, while $40.6 \%$ are not using. The result is more than Odimegwu (1999) in his factor analysis of FP attitudes and use in Nigeria who found out that $42 \%$ of men have ever used a traditional method or a modern method. The differences in results may be due to the different location of study. Among the different methods, $79.8 \%$ of respondents use the condom (similar to $92 \%$ in Olawepo and Okedare, (2006) finding), $16.0 \%$ use the withdrawal method and $4.2 \%$ use periodic abstinence. Breaking it down to marital status, $57.7 \%$ of the single respondents use FP, while $42.3 \%$ do not and $60.3 \%$ of married respondents use FP, while $39.7 \%$ do not. Also, $80.5 \%$ of respondents that are single use the condom, while $19.5 \%$ use the withdrawal method. For the married respondents, $61.2 \%$ use the condom, while $38.8 \%$ use the withdrawal method. The InDepth Interview is consistent with these findings with many of the interviewees stating preference for the use of condoms because they are cheap, readily available and do not need professional advice to use. It can also be observe that the number of married men using the withdrawal method is more than the number of singles.

This study was also able to establish a significant relationship between the knowledge and use of FP among respondents. The statistical result shows that $\mathrm{df}=2$, $\mathrm{p}<0.004$. However a comparison of results in this study shows that there is a great disparity between the knowledge of FP and the use of FP. While the knowledge level 
is very high at $95.6 \%$, the usage is put at $59.4 \%$. A lot still needs to be done to increase the number of Airmen using FP.

\section{Conclusion/recommendations}

The findings of this study suggest that the knowledge of FP among Airmen is very high with the mass media playing a significant role in the dissemination of information on FP. The services provided by the family planning unit in the NAF hospital are not properly accessed by Airmen.

For FP to be effective in the control of population growth, promote responsible parenthood and help people give birth to the number of children they can conveniently take cater for, especially as it concern Airmen, I humbly make the following recommendations based on the findings of this study;

1. There should be a liaison between FP service providers and the Authority of the NAF so as to formulate policies and programs geared towards encouraging Airmen to patronize the FP unit in the 445 NAF hospitals more. FP programs that recognise the importance of male role should be encouraged.

2. Other media that have direct impact on people can also be used to sensitize the people more about FP programs and services. Mass media like Billboards can be erected at strategic points in the base to deliver FP messages. The impact of Pamphlets, FP leaflets, and FP tracts should also be explored more. This will increase the knowledge of FP in the base generally.

3. Advocacy programs should also be embarked on so as to correct some misconception about FP. These misconceptions like side effects and some myth of FP sometimes are borne out of ignorance which can be corrected through the dissemination of the right information.

\section{References}

Almaz, Terefe \& Larson, C. P. (1993). Modern Contraception Use in Ethiopia: Does Involving Husbands Make A Difference?" American Journal of Public Health, 83(11): 1567-1576.

Caldwell, J. C., Philip, J. F., \& Barkat e-Khuda (2002). The Future of Family Planning. Studies in Family Planning, 33(1): 1-10.

Carling, A. (1992). Social Divisions. London: Verso.

Coleman, J. (1973). The Mathematics of Collective Action. London: Heinemann.

Coleman, J. S. (1990). Foundations of Social Theory. Cambridge: Belknap.

Elisabeth Rosenthal (2012). Nigeria tested by rapid rise in population. Retrieved on May 2nd 2012, from www.nytimes.com/2012/04/15/world/africa. 
Federal Government of Nigeria. (2004). National Population Policy.

Friedman, D. \& Hechter, M. (1988). The contribution of rational choice theory to macro Sociological research. Sociological Theory, 6(2): pp. 201-218

Heath, A. (1976). Rational Choice and Social Exchange. Cambridge: Cambridge University Press.

Isiugo-Abanihe, U. C. (1996). Women And Family Planning Practice In Nigeria.'In E. A. Oke and B. E. Owumi, Eds., Readings in Medical Sociology, Pp 104130. Ibadan: Resouce Development And Management Services.

Lundgren, R. I., Gribble, J. N., Greene, M. E., Emrick, G. E. and Margarita de Monroy (2005). Cultivating Men's Interest in Family Planning in Rural El Salvador. Studies in Family Planning, 36(3): 173-188.

National Population Commission (NPC) [Nigeria] \& ICF Macro (2009). Nigeria Demographic and Health Survey 2008. Abuja, Nigeria: National Population Commission and ICF Macro.

Nwokocha, E. E. (2006). Pregnancy Outcomes among the Ibani of Rivers State, Nigeria: Findings from Case-studies. African Population Studies, 21(1).

Odimegwu, C.O. (1999). Family Planning Attitudes and Use in Nigeria: A Factor Analysis. International Family Planning Perspective, 25(2): 86-91.

Olawepo, R. A. \& Okedare, E.A. (2006). Men's Attitudes towards Family Planning in a Traditional Urban Centre: An Example from Ilorin, Nigeria. Journal of Social Sciences. 13 (2): 83-90.

Parker, C. (2005). Adolescents and Emergency Contraceptive Pills in Developing Countries.

Pasquale, S. A. \& Cadoff, J. (1996). The Birth Control Book. New York: Ballantine Books.

Ringheim, K. (1996). Male Involvement and Contraceptive Methods for Men: Present and Future. Social Change Magazine, pp 1-8.

Toure, L. (1996). Male involvement in family planning: a review of the literature and selected program initiatives in africa.

United Nation Fund For Population Activities www.unfpa.org/../2010_worldpopulationprojection 